\title{
Face-to-Face Interactions of Postpartum Depressed and Nondepressed Mother-Infant Pairs at 2 Months
}

\author{
Jeffrey F. Cohn, Susan B. Campbell, Reinaldo Matias, and Joyce Hopkins \\ University of Pittsburgh
}

\begin{abstract}
Depression's influence on mother-infant interactions at 2 months postpartum was studied in 24 depressed and 22 nondepressed mother-infant dyads. Depression was diagnosed using the SADS-L and RDC. In S's homes, structured interactions of 3 min duration were videotaped and later coded using behavioral descriptors and a 1-s time base. Unstructured interactions were described using rating scales. During structured interactions, depressed mothers were more negative and their babies were less positive than were nondepressed dyads. The reduced positivity of depressed dyads was achieved through contingent responsiveness. Ratings from unstructured interactions were consistent with these findings. Results support the hypothesis that depression negatively influences motherinfant behavior, but indicate that influence may vary with development, chronicity, and presence of other risk factors.
\end{abstract}

Ten to $15 \%$ of postpartum women develop a moderate, clinically significant depressive reaction that is more prolonged than the "blues" and serious enough to interfere with daily functioning (O'Hara, Neunaber, \& Zekoski, 1984). Postpartum depression is thus a potentially important mental health problem for families with young infants. Studies of depression in the postpartum period, however, have focused almost exclusively on the woman herself (see Hopkins, Marcus, \& Campbell, 1984, for a review) and have ignored the possible negative effects depression may have on her relationship with her infant and her infant's development.

Postpartum depression would be expected to interfere with optimal mothering. The importance of positive expression and responsive caretaking in early infancy has been well documented in numerous studies (e.g., Ainsworth, Blehar, Waters, \& Wall, 1978; Belsky, Rovine, \& Taylor, 1984), whereas maternal insensitivity and unavailability have been associated with a range of difficulties in adaptation in infancy and early childhood (e.g., Sroufe, 1983).

Recent studies have confirmed earlier clinical observations by Weissman and Paykel (1974) about the negative impact of maternal depression on young children's development. Research on the offspring of women with major depressive disorders has indicated a range of cognitive and social problems in toddlers, preschoolers, and school age children (Beardslee, Bemporad, Keller, \& Klerman, 1983; Cytryn, McKnew, ZahnWaxler, \& Gershon, 1986; Sameroff, Seifer, \& Zax, 1982). In-

The research reported in this article was supported by National Institute of Mental Health Grant SR01 MH40867 to Jeffrey F. Cohn and Susan B. Campbell.

Marquita Elmore, Myrna Pollock, Sally Popper, and Shelley Ross conducted the home interviews. Clare Flanagan, Peter Hayashi, Patricia Huszar, and Reinaldo Matias coded interactions.

Correspondence concerning this article should be addressed to Jeffrey F. Cohn, Clinical Psychology Program, 4015 O'Hara Street, University of Pittsburgh, Pittsburgh, Pennsylvania 15260. fants of depressed mothers may be especially vulnerable (Beardslee et al., 1983; Radke-Yarrow, Cummings, Kuczynski, \& Chapman, 1985).

The reported studies on infants under 1 year (Cohn, Matias, Tronick, Lyons-Ruth, \& Connell, 1986; Field, 1984; Field et al., 1985; Field et al., 1988), however, are difficult to interpret. These studies have used screening measures rather than a standard clinical interview to diagnose depression. Garrison and Earls (1986) have noted recently that elevated levels of depressive symptoms may index a range of psychiatric disorders, and not just depression. In the postpartum period, in particular, a relatively poor correspondence exists between self-reported depressive symptoms and a clinical diagnosis of depression (Hopkins, Campbell, \& Marcus, 1987; O'Hara et al., 1984). Depression scales do not distinguish the vegetative symptoms of depression from the normal changes of parturition. Thus, studies of infants under 1 year suggest a link between infant disturbance and maternal symptomatology, but are not specific to maternal depression.

Also, subjects in these studies have been mother-infant pairs in which the mothers had elevated levels of depressive symptoms in the context of a range of other psychosocial risk factors, including poverty, family disruption, and child abuse or neglect (Cohn et al., 1986; Field, 1984; Field et al., 1985). These factors further complicate interpretation, because they are themselves related to childhood behavior disorder and psychopathology (Robins, 1974; Rutter et al., 1974).

These intepretative limitations notwithstanding, findings from studies of infants under 1 year have been consistent in demonstrating that a combination of self-reported depressive symptomatology and other psychosocial risk factors is associated with less affectively positive mother-infant interaction in the first 6 months of life. For example, Field (1984) reported that depressed mothers and their infants were less positive and more negative during a face-to-face interaction at 3 months.

Cohn (Cohn \& Tronick, 1989; Cohn et al., 1986) reported similar findings at 6 months in a small group of 13 mother- 
infant pairs from multiproblem families in which the mothers had high levels of depressive symptoms. The mother-infant interactions were strikingly unlike those that have been reported in low-risk groups. Unlike nondepressed mothers who, during face-to-face interactions, typically are positive in affective expression about one half of the time, the mothers in Cohn et al.'s study were withdrawn or interacted in an aggressive, intrusive way with few positive affective expressions. The babies' affective expressions, too, were seldom positive.

These studies by Field (1984; Field et al., 1985) and Cohn (Cohn \& Tronick, 1989; Cohn et al., 1986) have suggested that maternal depression has the negative impact on early mothering behavior that would be expected from clinical descriptions of depressive symptoms. Flat affect and social withdrawal or irritability characterize the interactions of most mothers in these studies. Moreover, the infants of these negative and withdrawn mothers are likewise atypical, showing only limited engagement with the environment, clearly suggesting the influence of negative maternal affect on infant behavior. However, because of the diagnostic and other concerns noted before, more rigorous replication of these initial findings is needed. Thus, in the current study, we limited our subjects to married, middle-class women-thereby ruling out other confounding risk factorsand used a standard, diagnostic interview.

During mother-infant face-to-face interactions, the major functional components of the mothers' behavior are its affective quality and its contingent relationship to the baby's behavior. Infants of nondepressed mothers have been shown to match their mother's level of affective expression (Beebe, Jaffe, Feldstein, May, \& Alson, 1985; Cohn \& Tronick, 1987; Tronick \& Cohn, 1989). This matching is achieved through a process of bidirectional influence (Beebe et al., 1985; Cohn \& Tronick, 1988b; Symons \& Moran, 1987). Nondepressed mothers and babies respond contingently to changes in the other's behavior (Cohn \& Tronick, 1988b; Symons \& Moran, 1987). Specifically, infants are most likely to become positive in expression after their mothers become positive, and mothers remain positive until their infants sober and look away (Cohn \& Tronick, 1987). When mothers violate this pattern and sober while their infants are positive, their babies avert gaze and turn away (Cohn \& Elmore, 1988). Thus, both the quality and timing of the mother's affect influence the infant's response during normal interactions.

It is unclear whether depressed mothers and infants also respond contingently to changes in the other's behavior. Field (1984) suggested that the babies of depressed mothers may be responding to the level of mothers' affect only. She described mothers' affect as unchanging, which implies that the timing of the maternal behavior did not influence infants' response. Cohn et al. (1986) reported a range of negative affects, but found that depressed mothers and their babies showed less contingent responsiveness to changes in the other's behavior. These studies suggest that depressed mothers show both lower levels of affective expression and less contingent responsiveness.

To investigate whether postpartum depressed mothers are less positive in affective expression, we observed both a structured face-to-face interaction and interactions that occurred spontaneously during the course of a home visit. Mothers' and babies' affect during face-to-face interactions was described us- ing behavioral descriptors on a 1-s time base. Affect during spontaneous interactions was described with more global rating scales. To determine whether depressed mothers were less responsive to changes in their infants' behavior during face-toface interactions, we used time-series techniques to quantify the mothers' contingent responsiveness to her baby. Using converging measures, we evaluated the influence of postpartum depression on mothers' and babies' affect and responsiveness.

In nondepressed mother-infant pairs, patterns of interaction change with development (Cohn \& Tronick, 1987, 1988b; Kaye \& Fogel, 1980), and the same is likely to be true for depressed mother-infant pairs. Moreover, the course of depressive symptoms may additionally influence interaction patterns. Longitudinal studies that examine both process and outcome are necessary to shed light on the mechanisms that lead to initial disruptions in infant behavior and to clarify how these disruptions are modified by developmental changes in the infant, by the course and severity of maternal depression, and by mother-infant transactions over time.

We report initial findings from a longitudinal study of the impact of postpartum depression on mother-infant interaction and infant development. We focus on the processes of motherinfant interaction across situations and over time in depressed postpartum women and a matched group of nondepressed postpartum women. We collect data at regular intervals during the first year of life, beginning at a younger age ( 2 months) than has previously been studied. Maternal depression, mother-infant reciprocity, and infant behavior are examined with convergent measures.

At 2 months postpartum, we observed mothers and babies in face-to-face interactions as well as during feeding and caretaking. Using both microanalytic and more global measures, we tested the following hypotheses: (a) Postpartum depressed women are less positive and more negative with their infants than a comparison group of nondepressed, postpartum women, (b) infants of depressed women are less positive and more negative with their mothers than are infants of comparison women, (c) both depressed and nondepressed mothers and babies match each other's level of affective expression, and (d) depressed mothers and babies are less responsive to changes in each other's behavior during face-to-face interaction than are comparison mother-baby pairs.

\section{Method}

\section{Subjects and Overview of Procedures}

Postpartum women were recruited from birth records at MageeWomen's Hospital, the principal obstetrics facility for the Pittsburgh area. Private patients residing in predominantly middle-class neighborhoods in Allegheny County were mailed a letter describing the study at about 6 weeks postpartum. They were telephoned at between 7 and 8 weeks postpartum by one of four project staff members; three of the staff members were advanced female graduate students in clinical psychology, and one was a BS-level female research assistant.

We contacted 693 women by phone; 596 , or $86 \%$, agreed to be screened to determine whether they met the following inclusion criteria: White, between 18 and 35 years of age, and married and living with spouse. In addition, only primiparous women who delivered healthy, full-term singletons without complications were considered for inclu- 
sion in the final sample; a total of 297 mother-infant dyads (50\% of those screened) met these criteria.

Women who met inclusion criteria were then screened further to determine whether they had experienced a clinically significant depression in the postpartum period. The semi-structured interview was a modified version of the Schedule for Affective Disorders and Schizophrenia (SADS; Endicott \& Spitzer, 1978). The interviewer assessed whether the woman had experienced a sustained period of sadness or depression, or any of the major symptoms of depression, within the last month. Interviewers were careful to take into account the normal changes of parturition. For instance, sleep disruption was not considered clinically significant if it was due to night-time feedings. Women who reported depressed mood and at least three major symptoms were considered to have met screening criteria for depression.

The phone interviews were supervised by a psychiatric social worker. Reliability among interviewers was not quantified. However, the diagnostic status of all of the women who participated in the study was checked at the time of the home visit, which was typically conducted by a different interviewer (an advanced female graduate student in clinical psychology or a psychiatric social worker). In only two cases was the initial determination of depression disconfirmed.

A total of 39 women (13\%) met screening criteria for postpartum depression and were invited to participate in a longitudinal study of postpartum adaptation and maternal mood. If they were willing to participate, a home visit was scheduled within a week of the telephone screening. Home visits were scheduled for a time when the infant would be awake and alert.

In all, 26 depressed women (67\%) agreed to schedule a home visit. Once a depressed subject was identified, the next woman on the list who did not meet depression screening criteria (i.e., no depressed mood for a sustained period of time and fewer than three symptoms) was also invited to participate in the study. Of the 45 nondepressed comparison women asked to participate in the study, $23(51 \%)$ agreed. One control subject dropped out after the home visit was scheduled. During the home visit, a more detailed assessment of depression was conducted on both depressed women and nondepressed comparison women (see discussion later). Only women who met Research Diagnostic Criteria (RDC; Spitzer, Endicott, \& Robins, 1978) for depression were included in the depressed group.

The final sample consisted of 24 women who met RDC for depression (19 for major depression) and 22 nondepressed control participants. The groups were well matched on demographic variables. Depressed women had a mean age of 28.9 years, as compared with 29.9 for control subjects. All of the subjects had completed high school, and $87 \%$ had gone beyond high school; $59 \%$ had obtained at least a college degree. However, $20 \%$ of the depressed women had returned to work at least 20 hr a week, as compared with none of the control participants (Fisher's exact test, $p=.03$ ).

Depressed women who were working $20 \mathrm{hr}$ or more did not differ in demographic characteristics from the rest of the sample, nor did they differ in severity of depression from those depressed women who were home full time or working less than $20 \mathrm{hr}$ a week. However, their work status meant that a substantial part of infants' care was provided by someone else. We statistically controlled for work status in the data analyses.

The 24 infants of depressed mothers and 22 infants of nondepressed mothers were well matched on gender (equal proportions of boys and girls in each group), age (9.0 weeks vs. 8.8 weeks), and birth weight $(3,420 \mathrm{~g}$ vs. $3,450 \mathrm{~g})$.

\section{Assessment of Depression}

The SADS (Endicott \& Spitzer, 1978) is a well-standardized, structured interview based on the RDC (Spitzer et al., 1978), which com- prises operationally defined inclusion and exclusion criteria for depression and other disorders. A modified version of the SADS interview was used to diagnose postpartum depression. Severity of dysphoric mood and each of the eight major symptoms of depression (appetite loss, sleep problems, loss of energy, loss of interest, guilt, concentration difficulties, psychomotor agitation or retardation, and suicidal ideation) were rated from 1 to 6, with a higher score indicating greater severity. A rating equal to or greater than 3 was necessary for a symptom to be considered clinically significant. These ratings were adjusted to take into account changes expected in the postpartum period. For example, sleep-continuity problems due to night-time feedings were not considered clinically significant; appetite increase and lack of interest in sex likewise did not contribute to diagnosis. Furthermore, interviewers went to great lengths, using standard probes, to determine whether a particular symptom was due to the mood disturbance or to the sequelae of childbirth and infant caretaking. Women had to endorse dysphoric mood lasting at least 2 weeks and four of eight symptoms to receive a diagnosis of major depression; women endorsing dysphoric mood and three of eight symptoms met criteria for minor depression. In addition, in keeping with the RDC, women had to indicate that they had sought help ( $n=$ 4) or experienced significant functional impairment in order to receive a diagnosis of depression.

\section{Interviewer Training and Reliability of Diagnoses}

Interviews were conducted by four women who usually visited the home in pairs. All of the interviews were audiotaped. The primary interviewer, a psychiatric social worker who was also an experienced SADS interviewer, trained the other three interviewers, all women graduate students in clinical psychology. Training included 16 pilot interviews and was conducted under the supervision of one of the authors (JH), who has extensive experience using the SADS with a postpartum population (Hopkins et al., 1987). Data collection did not begin until interviewers had established perfect agreement for diagnosis.

Once data collection had begun, the consistency of diagnostic classifications was assessed by comparing interviewers' diagnoses with independent diagnoses made from the audiotaped interviews of 14 subjects. Agreement for diagnosis between the primary interviewer and the three graduate student interviewers was $100 \%$.

\section{Face-to-Face Interaction}

Procedures. The face-to-face interaction consisted of $3 \mathrm{~min}$ of normal interaction in which mothers were asked to "play with your baby." Mothers sat in a chair and either supported their babies in their laps or, in a few cases, positioned them in an infant seat. If the baby became fussy within $15 \mathrm{~s}$ of the start, we stopped the interaction and tried again later. Of the interactions, 13 required a second attempt $(9$ depressed, 4 nondepressed; Fisher's exact test, $p=.11$ ); 12 were satisfactorily completed and one (a depressed subject) was not, because of repeated fussiness.

Interactions were videotaped using two tripod-mounted, portable videocameras yoked to a split-screen generator, which provided frontal views of both mother and baby. Interviewers sat in another room whenever possible and monitored the interaction on a small videomonitor (Sony Watchman).

Coding. For both partners, we coded facial and vocal affective expression, direction of gaze, body posture, and movement on separate passes of the videotape using descriptors based on Tronick's (Cohn \& Tronick, 1987; Tronick, Als, \& Brazelton, 1980) monadic phases and Izard's (Izard, Dougherty, \& Hembree, 1983) system for identifying affect expressions by holistic judgments (Affex). The molecular codes were recoded to form five levels of engagement, varying from negative to positive: negative, look away, attend, low positive, and high positive (Table 1). 
Table 1

Mothers' and Babies' Affective Engagement States

\begin{tabular}{cl}
\hline Scaled score & State \\
\hline 1 & $\begin{array}{l}\text { Negative (.99). Facial or vocal expressions of anger, sadness, or irritation. Intrusive } \\
\text { handling or disinterest. }\end{array}$ \\
2 & $\begin{array}{l}\text { Look away (.99). Neutral facial or vocal expression with gaze directed away from the } \\
\text { baby. }\end{array}$ \\
3 & $\begin{array}{l}\text { Attend (.85). Neutral facial or vocal expression and gaze directed toward the baby. } \\
\text { Low positive (.87). Simple smile, with corners of mouth turned up and cheeks raised, and } \\
\text { gaze directed toward the baby. Positive vocalizations. } \\
\text { High positive (.86). Exaggerated facial or vocal expressions (e.g., mock-surprise) or } \\
\text { smiling combined with rhythmic vocalizations or body movements. }\end{array}$ \\
5 & $\begin{array}{l}\text { Begative (.94). Fuss/cry or wary expressions. } \\
\text { Look Away (.87). Facial expression of neutral affect or interest, with gaze directed away } \\
\text { from the mother. }\end{array}$ \\
2 & $\begin{array}{l}\text { Attend (.86). Defined as for the mother. } \\
\text { Low positive (.86). Interest expressions, as defined by Izard, Dougherty, and Hembree } \\
\text { (1983), with gaze directed toward the mother. } \\
\text { High positive (.92). Simple or broad smile or laughing. }\end{array}$ \\
\hline
\end{tabular}

Note. Interobserver agreement is shown in parentheses.

Mother and baby behaviors were scored independently by coders blind to subject diagnosis. Coders viewed the videotape in real time. Whenever a change in behavior was observed, the videotape was reversed and replayed at either full or slow speed to determine whether and what type of change had occurred and the time of its occurrence. Times, read from a digital display recorded on the videotapes, were rounded to the nearest $1 \mathrm{~s}$. From this record of the onset times of behavior changes, we produced a continuous time series of each partner's affective engagement during the interaction.

Interobserver agreement. To assess interobserver agreement, videotapes of one third of the mothers and one third of the babies were recoded independently by comparison coders. Agreement, defined as the comparison coder observing the same engagement state at the same time on the videotape as observed by the original coder, ranged from $85 \%$ to $99 \%$ for mothers' states (Table 1) and from $86 \%$ to $94 \%$ for babies' states (kappa coefficients $=.74$ and .73 , respectively).

\section{Home Observations}

At the end of the home visit, staff completed rating scales descriptive of the mother's and baby's behaviors. Included were 11 mother-rating scales and 5 baby-rating scales, which were adapted from those used in previous research: Maternal Sensitivity (Ainsworth et al., 1978), Maternal Affective Expression (Cohn et al., 1986; Lyons-Ruth, Connell, Zoll, \& Stahl, 1987; Vaughn, Taraldson, Crichton, \& Egeland, 1980), and the Baby's Predominant Mood and Responsiveness (Vaughn et al., 1980). The number of anchor points for the scales ranged from 3 to 5 . The scales quantified the home visitors' subjective impressions at the conclusion of their 2-3 hr in the home, during which mother and baby were observed during feeding and routine caretaking.

Whenever more than a few rating scales are used, they tend to be intercorrelated. Both to examine collinearity and to increase the reliability of test statistics, we factor analyzed (principal components with varimax rotation) the mother and baby rating scales.

Reliability. Home visitors were trained to $80 \%$ reliability on practice tapes, home visits with pilot subjects, and actual interviews and assess- ments with our first 8 subjects. Data from the latter were omitted from all of the analyses. Home visitors also participated in periodic training once data collection had begun. They were not blind to diagnosis, however, and no means existed to obtain comparison ratings. Thus, the ratings should be interpreted cautiously.

The rating-scale and face-to-face measures both assess affective behavior. They differ in the extent of behavior sampled (i.e., the entire visit vs. only the play interaction) and the method of description (molar, subjective ratings vs. molecular behavior codes). Correlations between the two sets of measures are reported later.

\section{Results}

\section{Face-to-Face Interactions}

Interactions were intended to last $3 \mathrm{~min}$, but in practice they varied slightly in both duration and number of uncodeable seconds of videotape. Because we were videotaping in subjects' homes rather than in a controlled laboratory setting, short segments of interaction would occasionally be uncodeable when, for example, one subject's movement blocked our view of the other. So that test statistics would not be biased, we converted all duration data to proportions of total codeable interaction time. Because the means and variances of proportions are not independent, all proportions were logit transformed before analysis (Cohen \& Cohen, 1983).

To control for work status among depressed mothers, we used analysis of variance with planned contrasts to compare nonworking depressed and nondepressed mothers of male and female infants. For contrasts involving categorical data, we used Fisher's exact test to compare nonworking depressed and nondepressed mothers and infants. We also compared nonworking and working depressed mothers and infants to evaluate the possible interaction between depression and work status. Because 
Table 2

Mean Proportion of Mothers' Time in Negative and Positive States

\begin{tabular}{lllll}
\hline Group & $n$ & Negative & Low positive & High positive \\
\hline Nondepressed & & & & \\
Nonworking & 22 & .00 & .42 & .23 \\
Boys & 11 & .00 & .43 & .16 \\
$\quad$ Girls & 11 & .00 & .41 & .29 \\
Depressed & & & & \\
Nonworking & 18 & $.04^{\mathrm{n}}$ & .33 & .19 \\
$\quad$ Boys & 10 & .01 & $.23^{\mathrm{b}}$ & .24 \\
$\quad$ Girls & 8 & .07 & .46 & .12 \\
Working & 5 & .00 & $.57^{\mathrm{c}}$ & .12 \\
\hline
\end{tabular}

Note. Working $=$ employed outside of the home more than $20 \mathrm{hr}$ per week.

- Significantly different from nondepressed, nonworking; planned comparison, $F(1,40)=5.15, p<.05$. ' Significantly different from both nonworking depressed mothers of girls and nonworking nondepressed mothers of boys and giris; planned comparison, $F(1,40)=4.12, p<$ .05. 'Significantly different from nonworking depressed; planned comparison, $F(1,40)=5.90, p<.05$.

of the small number of infants in the working group ( 2 boys and 3 girls), we were unable to evaluate the interaction between sex and work status within the depressed group.

Are depressed mothers more negative and less positive than nondepressed mothers? Mother negative consisted of irritation or, in one instance, disinterest. Nonworking depressed mothers had a higher proportion of negative expressions (Table 2). They were also more likely to show any negative expression: $28 \%$ (5 of 18) of nonworking depressed mothers expressed negative affect, as compared with $5 \%$ ( 1 of 22 ) of nondepressed mothers (Fisher's exact test, $p=.05$, one-tailed). Look away occurred $1 \%$ or less of the time in each group, and so was not analyzed.

Nonworking depressed mothers of boys had a significantly lower proportion of low positive than did nonworking depressed mothers of girls or nondepressed mothers of boys or girls. Within the depressed group, nonworking depressed mothers had a lower proportion of low positive than working depressed mothers.

Are babies of depressed mothers more negative and less positive than those of nondepressed mothers? Maternal depression was unrelated to the proportion of babies' negative affect (Table 3). Babies of nonworking depressed mothers had lower proportions of low positive (i.e., interest) than did babies of nondepressed mothers or than babies of depressed mothers who worked. Baby high positive did not vary significantly as a function of depression or work status.

Do depressed and nondepressed mothers and babies differ in the extent to which they match each other's level of affective expression? To answer this question, we evaluated the joint distributions of the proportions of time spent in negative and positive states using hierarchical multiple regression. Mother and baby negative were strongly related $(R=.47, p<.01)$, but only in the depressed group. Only one nondepressed mother was ever negative, and then only briefly. Composite scores for mother and baby positive (low positive + high positive) were also strongly related $(R=.61, p<.001)$ with no differential validity (i.e., slope bias) related to depression, infant's sex, or mother's work status. Both depressed and nondepressed mothers and babies matched each other's mean level of affective expression.

Are depressed mothers and babies less responsive to changes in each other's behavior than are nondepressed mothers and babies? To assess the contingent responsiveness of mothers and babies (i.e., bidirectional influence), we used bivariate Autoregressive Integrated Moving Average (ARIMA) time-series analysis (McCleary \& Hay, 1980). For these analyses, the 5-point, scaled engagement scores were used (see Cohn \& Tronick, 1988a, 1988b). For each dyad, we analyzed the longest continuous series of codeable observations, unless it included fewer than 50. With ARIMA methods, a time series of less than about 50 observations compromises statistical power and can yield biased parameter estimates (McCleary \& Hay, 1980). Time series of one working and four nonworking depressed dyads were excluded for this reason. The time series of the depressed and nondepressed dyads that we analyzed did not significantly vary in length ( $M$ length $=120 \mathrm{~s}$ and $107 \mathrm{~s}$, respectively), $F(1,40)=$ $.98, p>.1$. For each dyad, we conducted individual time-series analyses.

Cross-correlations between two time series are confounded by within series (auto-) correlation. Univariate ARIMA techniques were used to remove autocorrelation from each time series (see Cohn \& Tronick, 1988b, for a description of this approach). We then computed cross-correlated functions from the residual series for each mother-infant pair. A finding of no statistically significant cross correlations (i.e., all cross correlations within $2 S D$ s of zero) is sufficient evidence to rule out influence of either partner on the other. Where significant cross correlations were found, we followed the procedure of $\mathrm{Mc}$ Cleary and Hay (1980) to test the null hypothesis that mother's and infant's behaviors are independent.

We compared both the proportions of mothers and babies in the nonworking depressed and nondepressed groups who were responsive to changes in the partner's behavior and the proportion of variance accounted for by responsiveness to changes in the partner's behavior. For the former analysis, we pooled across sex of infant to increase statistical reliability. For the latter analysis, we conducted planned comparisons, as before.

Table 3

Mean Proportion of Babies' Time in

Negative and Positive States

\begin{tabular}{lrccc}
\hline Group & $n$ & Negative & Low positive & High positive \\
\hline Nondepressed & & & & \\
Nonworking & 22 & .12 & .29 & .13 \\
$\quad$ Boys & 11 & .12 & .31 & .08 \\
$\quad$ Girls & 11 & .12 & .26 & .18 \\
Depressed & & & & \\
Nonworking & 18 & .24 & $.15^{\mathrm{a}}$ & .10 \\
$\quad$ Boys & 10 & .30 & .15 & .09 \\
$\quad$ Girls & 8 & .16 & .14 & .12 \\
Working & 5 & .13 & $.37^{\mathrm{b}}$ & .18 \\
\hline
\end{tabular}

Note. Working $=$ employed outside of the home more than $20 \mathrm{hr}$ per week.

"Significantly different from nondepressed, nonworking; planned comparison, $F(1,40)=4.62, p<.05$. 'bignificantly different from nonworking depressed; planned comparison, $F(1,40)=4.37, p<.05$. 
Table 4

Proportion of Mothers and Babies Who Were Responsive to Changes in the Other's Behavior

\begin{tabular}{lrcc}
\hline Group & $n$ & Mothers & Babies \\
\hline $\begin{array}{l}\text { Nondepressed } \\
\text { Nonworking }\end{array}$ & 22 & .45 & \\
Depressed & & & .50 \\
$\quad$ Nonworking & 14 & .57 & .45 \\
Working & 4 & .75 & .75 \\
\hline
\end{tabular}

Note. Data are pooled across sex of infant.

Mothers and babies in each group were equally likely to respond contingently to changes in the partner's behavior (Fisher's exact test, $p=.37$, for mothers, and $p=.53$, for babies) (Table 4). Within the depressed group, working status was unrelated to mothers' or babies' responsiveness (Fisher's exact test, $p=.49$ and $p=.71$, respectively).

The size of bidirectional effects was also similar between the nonworking depressed and nondepressed groups and was unrelated to infants' sex. The mean proportions of variance accounted for by bidirectional effects were as follows: $4 \%$ for both nonworking depressed and nondepressed mothers, $4 \%$ for babies of nonworking depressed mothers, and $5 \%$ for babies of nonworking nondepressed mothers. These proportions of variance are similar to those reported in mother-infant pairs at 9 months by Jasnow and Feldstein (1986). We found no differences related to work status within the depressed group. Thus, bidirectional influence characterized the interactions of both depressed and nondepressed mother-infant pairs to a comparable extent.

\section{Home ratings}

Factor analyses. Principal components factor analysis of the mothers' scales resulted in a two-factor solution. Factor 1, which we labeled Mother's Affect, accounted for $51 \%$ of the variance, with high positive loadings $(.82$ to .92$)$ on Warmth, Positive Affect, and Delight, and moderate to high negative loadings $(-.68$ to -.83$)$ on Flatness of Affect, Disengagement, and Negative Affect. Factor 2, which we labeled Mother's Sensitivity, accounted for an additional $15 \%$ of variance, with moderate to high positive loadings (.78 to .85 ) on Ainsworth et al.'s (1978) Sensitivity Scale and Quality of Caretaking, and a moderate negative loading ( -.77$)$ on Interfering Manipulation.

A second principal components factor analysis of the babies' scales also resulted in a two-factor solution. Factor 1 accounted for $43 \%$ of the variance, with moderate loadings (.63 to .78 ) on three scales: Predominant Mood, Cuddling, and Responsiveness. Factor 2 accounted for an additional $19 \%$ of variance, with a high loading (.91) on Elicits Mother and moderate loading (.62) on Elicits Home Visitor. This second factor was omitted from further analyses inasmuch as babies varied in their opportunity to interact with the home visitor, and eliciting social interaction is unreliable before 6 months of age (Cohn \& Tronick, 1987; Kaye \& Fogel, 1980).

Relationship of face-to-face and home-rating measures. To assess the generalizability of the home-rating factor scores, we compared them with data from the face-to-face interaction. Factor scores for home ratings of mothers' and babies' affect were significantly correlated with corresponding measures of mothers' and babies' affect during face-to-face interaction (Table 5). Maternal Sensitivity (Factor 2) was unrelated to mothers' or babies' affect during the face-to-face interaction.

Ratings of affective expression. Consistent with the face-toface interaction data, nonworking depressed mothers were less positive (Factor 1) than were nonworking nondepressed mothers (Table 6), and the two groups were equal on sensitivity. Working and nonworking depressed mothers did not differ on either measure. Babies of nonworking depressed mothers showed a trend, $F(1,32)=2.79, p=.10$, that suggested less positive affect than did babies of nonworking nondepressed mothers. We found no differences related to mothers' work status in ratings of babies' affect.

\section{Discussion}

Previous reports about the influence of maternal depression during the first year have used symptom ratings on brief questionnaires rather than a standard clinical interview and Research Diagnostic Criteria. Results from these studies suggested that depressed mothers and their babies were more negative and less positive than those of nondepressed mother-infant pairs. Using Research Diagnostic Criteria and carefully controlling for possible confounds, we found partial support at 2 months postpartum for these earlier findings.

Depressed mothers showed increased negative affect, primarily irritation or intrusiveness during the face-to-face interaction. Both the proportion of depressod mothers showing negative affect and the proportion of negative affect they displayed were significantly greater than that observed among nondepressed women. The difference in negative affect we found between depressed and nondepressed mothers was comparable with that reported at 3 months by Field (1984), but less than that reported by Cohn et al. (1986) at 6 months. Field found that the frequency of negative expression was approximately four times greater among depressed than among nondepressed

Table 5

Relationship Between Home-Rating and Face-to-Face Measures of Mothers' and Babies' Affect

\begin{tabular}{lccc}
\hline & \multicolumn{3}{c}{ Home ratings } \\
\cline { 2 - 3 } & \multicolumn{2}{c}{ Mother } & Baby \\
\cline { 2 - 3 } & Affect & Sensitive & Affect \\
\hline Face-to-Face & & & \\
\hline Mother & .04 & .16 & .00 \\
Negative & .13 & -.06 & .15 \\
Low positive & $.57^{* *}$ & -.02 & $.40^{*}$ \\
High positive & & .22 & $-.31^{*}$ \\
Baby & -.26 & -.16 & $.35^{*}$ \\
Negative & $.39^{* *}$ & -.05 & $.43^{* *}$ \\
Low positive & $.39^{* *}$ & & \\
High positive & & &
\end{tabular}

$* p<.05$, one-tailed. ** $p<.01$, one-tailed. 
Table 6

Means and Standard Deviations of Factor Scores From Home Ratings

\begin{tabular}{|c|c|c|c|c|c|c|c|}
\hline \multirow[b]{3}{*}{ Group } & \multirow[b]{3}{*}{$n$} & \multicolumn{4}{|c|}{ Mother } & \multirow{2}{*}{\multicolumn{2}{|c|}{$\frac{\text { Baby }}{\text { Affect }}$}} \\
\hline & & \multicolumn{2}{|c|}{ Affect } & \multicolumn{2}{|c|}{ Sensitive } & & \\
\hline & & $M$ & $S D$ & $M$ & $S D$ & $M$ & $S D$ \\
\hline \multicolumn{8}{|l|}{ Nondepressed } \\
\hline Nonworking & 20 & 0.49 & 0.58 & 0.07 & 0.86 & 0.26 & 0.96 \\
\hline Boys & 10 & 0.51 & 0.46 & 0.14 & 0.55 & -0.06 & 0.88 \\
\hline Girls & 10 & 0.46 & 0.70 & 0.01 & 1.12 & 0.55 & 0.98 \\
\hline \multicolumn{8}{|l|}{ Depressed } \\
\hline Nonworking & 13 & $-0.49^{\mathrm{a}}$ & 1.15 & -0.06 & 1.01 & -0.29 & 0.75 \\
\hline Boys & 7 & -0.61 & 1.55 & 0.06 & 0.69 & -0.34 & 0.86 \\
\hline Girls & 6 & -0.35 & 0.53 & -0.21 & 1.35 & -0.23 & 0.66 \\
\hline Working & 4 & -0.83 & 1.17 & -0.16 & 1.86 & 0.21 & 1.06 \\
\hline
\end{tabular}

- Significantly different from nondepressed, nonworking; planned comparison, $F(1,32)=8.96, p<.01$.

mothers, which is comparable with what we found for proportion data. Cohn et al. (1986), on the other hand, found much higher percentages of negative affect than we did. Almost one half of the depressed women in their study were affectively negative one fourth or more of the time.

The difference between our data and Field's (1984), on the one hand, and Cohn et al.'s (1986), on the other, suggests a possible increase in negativity over time if depression continues. A chronicity effect would be consistent with Sameroff, Seifer, and Zax (1982), who reported that chronicity was at least as important as diagnostic status alone. The women in the study by Cohn et al. had stable, clinically significant levels of depressive symptoms over at least one year's time. Another possibility, of course, is that higher levels of negative affect result from the addition of multiple risk factors, which characterized the Cohn et al. study. Because we have subsequently studied a larger number of depressed women and have carefully controlled for potentially confounding factors, our results may be more representative.

During the face-to-face interaction, depressed mothers of boys, although not of girls, were less positive. We had not anticipated this interaction between gender and depression. Research on affect expression in normal mother-infant pairs has been inconsistent in regard to gender. Several large studies have found no gender effects (e.g., Cohn \& Tronick, 1987; Kaye \& Fogel, 1980). Some studies that have, however, have found effects consistent with the one we report. Haviland (1977) found that mothers tended to ignore negative expressions in daughters more so than in sons. Malatesta and Haviland (1986), on the other hand, found that mothers of full-term female infants responded more contingently than did mothers of boys to negative expressions, which implies increased negative expressions among mothers of girls. We are cautious about interpreting this interaction between depression and infant gender, however, because we did not find it in the home-rating data. Longitudinal analyses of our data will permit us to evaluate the relation between depression and infants' gender.

We found that interactions of postpartum depressed and nondepressed mother-infant pairs at 2 months showed an equivalent extent of bidirectional influence. Both the proportion of subjects responsive to changes in the partner's behavior and the proportion of variance related to bidirectional effects were unrelated to mother's diagnostic status. Prior research has questioned whether depressed mothers and babies at older ages are responsive to each other. Field (1984) emphasized the unchanging nature of the depressed mother's affective expression, its consistent flatness and relative lack of positive expression. Similarly, Cohn et al. (1986) pointed to the lack of contingent responsiveness between depressed mothers and their babies. Whether or not this characterization is correct at older ages, we found no support for it at 2 months. Depressed mothers and babies were no less responsive to each other than were nondepressed mothers and babies. The groups differed in their level of affective expression, but not in the contingent relationship between mothers' and infants' behavior.

If face-to-face interactions were characterized by a lack of responsiveness, the effects of depression could be more severe. Cohn and Tronick (1983) found that even brief experience with simulated maternal depression at 3 months resulted in continued infant negativity even after the mother again interacted normally. Field (1984) observed a similar carry-over of affect from one type of interaction to another, which she attributed to reduced responsiveness; and more recently Field et al. (1988) found that infants of depressed mothers showed diminished positive affect even in interactions with nondepressed women. Cohn et al. (1986) noted that infants of depressed mothers showed a lack of interest in their mothers and also in objects. Taken together, these findings suggest a shift with development from contingent responsiveness at 2 months to an attenuated involvement with persons and objects later in the first year. This shift would have significant implications for the infant's ability to change in response to a remission of maternal depression, as well as for the infant's developmental competence (cf. Tronick, Ricks, \& Cohn, 1982). Our design will enable us to evaluate this hypothesis.

Analyses of the home ratings closely paralleled those from the observations of face-to-face interaction. Depressed mothers were rated less positively than nondepressed mothers, and their babies tended to be rated less positively than babies of nondepressed mothers. Although the home visitors who made the ratings were not blind to diagnosis, the significant correlations we found between face-to-face and home-observation measures suggest that the ratings were not biased. The absence of significant group differences on the home-rating measure of sensitivity also contraindicated systematic bias, inasmuch as bias would be expected to influence all ratings equally. The results regarding sensitivity were also consistent with those for bidirectional influence. These findings lead us to conclude that affective behavior generalized from face-to-face interactions to other contexts.

One provocative finding in the face-to-face data was that of an interaction between work status and depression. Working depressed mothers and their infants generally were more positive than nonworking depressed mothers and babies and resembled nondepressed comparison dyads. This finding must be viewed with caution inasmuch as (a) the number of working depressed women was small, (b) we had no a priori hypotheses about work status, and (c) the differential effect of work-status was not repli- 
cated in the home ratings. Nevertheless, we found the effect on several of the face-to-face measures. Work outside of the home may have provided adjunct social support that enabled some depressed mothers to feel better about their babies. On the other hand, depressed working women were no less depressed than those not working, which argues against a positive role for extensive involvement outside the home.

One possibility is that the depressed mother who is employed outside the home learns to manage her affective expression better, so that there is a discrepancy between what she feels and expresses. Ekman (1984) described referential expressions as ones that are discrepant with the underlying emotion. It would be important to know whether referential expressions are more common among working depressed mothers, and whether babies are less able than adults to discriminate between referential and "true" expressions. More detailed studies of facial expression in depressed women, using anatomically based affect measurement systems such as Ekman's (1984) or Izard et al.'s (1983) may be needed to pursue this hypothesis. Developmental studies of infants' ability to discriminate referential expressions are also indicated.

Work status may also influence interactions one other way. The baby of a working mother must be cared for by someone else much of the time. Alternative caregiving provides the baby with less exposure to depression, shields the mother from continual demands of caregiving, and may increase the mother's stimulus value for the baby. Because she is less often present, she may be less familiar to the baby and hence a more novel stimulus. Consistent with this hypothesis, we found significantly increased low positive expressions, (i.e., interest) among babies of working mothers. The infant's heightened interest in the mother may draw her out, making her more positive and decreasing the influence of her depression on the dyadic interaction.

In summary, during face-to-face interactions, depressed mothers and their babies were less positive than nondepressed, comparison mothers and babies, with the exception of those depressed mothers who were working outside of the home more than $20 \mathrm{hr}$ per week. The reduced positivity of depressed mother-infant interactions was brought about through contingent responsiveness to affective displays, rather than through a lack of responsiveness to changes in the partner's ongoing behavior. Mothers' and babies' affective behavior generalized from face-to-face interactions to other contexts in the home. The impact of depression may undergo change with development over the first year.

\section{References}

Ainsworth, M. D., Blehar, M. C., Waters, E., \& Wall, S. (1978). Patterns of attachment: A psychological study of the strange situation. Hillsdale, NJ: Erlbaum.

Beardslee, W. R., Bemporad, J., Keller, M. B., \& Klerman, G. L. (1983). Children of parents with major affective disorder: A review. American Journal of Psychiatry, 140, 825-832.

Beebe, B., Jaffe, J., Feldstein, S., May, K., \& Alson, D. (1985). Interpersonal timing: The application of an adult dialogue model to motherinfant vocal and kinesic interactions. In T. Field \& A. Fogel (Eds.), Social perception in infants (pp. 217-248). Hillsdale, NJ: Erlbaum.

Belsky, J., Rovine, M., \& Taylor, D. G. (1984). Pennsylvania infant and family development project: III. The origins of individual differences in infant-mother attachment: Maternal and infant contributions. Child Development, 55, 718-728.

Cohen, J., \& Cohen, P. (1983). Applied multiple regression/correlation analysis for behavioral sciences (2nd ed.). Hillsdale, NJ: Erlbaum.

Cohn, J. F., \& Elmore, E. (1988). Effect of contingent changes in mothers' affective expression on the organization of behavior in 3-monthold infants. Infant Behavior and Development, 11, 493-505.

Cohn, J. F., Matias, R., Tronick, E. Z., Lyons-Ruth, K., \& Connell, D. (1986). Face-to-face interactions, spontaneous and structured, of mothers with depressive symptoms. In T. Field \& E. Z. Tronick(Eds.), Maternal depression and child development (New Directions for Child Development, No. 34, pp. 31-46). San Francisco: Jossey-Bass.

Cohn, J. F., \& Tronick, E. Z. (1983). Three-month-old infants' reaction to simulated maternal depression. Child Development, 54, 185-193.

Cohn, J. F., \& Tronick, E. Z. (1987). Mother-infant face-to-face interaction: The sequence of dyadic states at 3,6, and 9 months. Developmental Psychology, 23, 68-77.

Cohn, J. F., \& Tronick, E. Z. (1988a). Discrete versus scaling approaches to the description of mother-infant face-to-face interaction: Convergent validity and divergent applications. Developmental Psychology, 24, 396-397.

Cohn, J. F., \& Tronick, E. Z. (1988b). Mother-infant interaction: Influence is bidirectional and unrelated to periodic cycles in either partner's behavior. Developmental Psychology, 24, 386-392.

Cohn, J. F., \& Tronick, E. Z. (1989). Specificity of infants' response to mothers' affective behavior. Joumal of the American Academy of Child and Adolescent Psychiatry, 28, 242-248.

Cytryn, L., McKnew, D. H., Zahn-Waxler, C., \& Gershon, E. S. (1986). Developmental issues in risk research: The offspring of affectively ill parents. In M. Rutter, C. E. Izard, \& P. B. Read (Eds.), Depression in young people: Developmental and clinical perspectives (pp. 163-188). New York: Guilford.

Ekman, P. (1984). Expression and the nature of emotion. In K. R. Scherer \& P. Ekman (Eds.), Approaches to emotion (pp. 319-344). Hillsdale, NJ: Erlbaum.

Endicott, J., \& Spitzer, R. L. (1978). A diagnostic interview: The Schedule for Affective Disorders and Schizophrenia. Archives of General Psychiatry, 35, 837-844.

Field, T. (1984). Early interactions between infants and their postpartum depressed mothers. Infant Behavior and Development, 7, 527532.

Field, T., Healy, B., Goldstein, S., Perry, S., Debra, B., Schanberg, S., Zimmerman, E. A., \& Kuhn, C. (1988). Infants of "depressed" mothers show depressed behavior even with nondepressed adults. Child Development, 59, 1569-1579.

Field, T., Sandberg, D., Garcia, R., Vega-Lahr, N., Goldstein, S., \& Guy, L. (1985). Pregnancy problems, postpartum depression, and early mother-infant interactions. Developmental Psychology, 21, 11521156.

Garrison, W. T., \& Earls, F. J. (1986). Epidemiologic perspectives on maternal depression and the young child. In T. Field \& E. Z. Tronick (Eds.), Maternal depression and child development (New Directions for Child Development, No. 34, pp. 13-30). San Francisco: JosseyBass.

Haviland, J. (1977). Sex-related pragmatics in infants. Journal of Communication, 27, 80-84.

Hopkins, J., Campbell, S. B., \& Marcus, M. (1987). Role of infant related stressors in postpartum depression. Journal of Abnormal Psychology, 96, 237-241.

Hopkins, J., Marcus, M., \& Campbell, S. B. (1984). Postpartum depression: A critical review. Psychological Bulletin, 95, 498-515.

Izard, C. E., Dougherty, L. M., \& Hembree, E. A. (1983). A system for 
identifying affect expressions by holistic judgments (Affex). Newark: University of Delaware, Instructional Resources Center.

Jasnow, M., \& Feldstein, S. (1986). Adult-like temporal characteristics of mother-infant vocal interaction. Child Development, 57, 754-761.

Kaye, K., \& Fogel, A. (1980). The temporal structure of face-to-face communication between mothers and infants. Developmental Psychology, 16, 454-464.

Lyons-Ruth, K., Connell, D. B., Zoll, D., \& Stahl, J. (1987). Infants at social risk: Relations among infant maltreatment, maternal behavior, and infant attachment behavior. Developmental Psychology, 23, 223232.

Malatesta, C. Z., \& Haviland, J. M. (1986). Emotion socialization and expressive development in preterm and full-term infants. Child Development, 57, 316-330.

McCleary, R., \& Hay, R. A. (1980). Applied time series analysis for the social sciences. Beverly Hills, CA: Sage.

O'Hara, M. W., Neunaber, D. J., \& Zekoski, E. M. (1984). Prospective study of postpartum depression: Prevalence, course, predictive factors. Journal of Abnormal Psychology, 93, 158-171.

Radke-Yarrow, M., Cummings, E. H., Kuczynski, L., \& Chapman, M. (1985). Patterns of attachment in two- and three-year-olds in normal families and families with parental depression. Child Development, $56,884-893$.

Robins, L. (1974). Deviant children grown up. New York: Krieger.

Rutter, M., Yule, B., Quinton, D., Rowland, O., Yule, W., \& Berger, M. (1974). Attainment and adjustment in two geographical areas: III. British Journal of Psychiatry, 123, 520-533.

Sameroff, A., Seifer, R., \& Zax, M. (1982). Early development of children risk for emotional disorder. Monographs of the Society for Research in Child Development, 47 (7, Serial No. 199).
Spitzer, R. L., Endicott, J., \& Robins, E. (1978). Research Diagnostic Criteria: Rationale and reliability. Archives of General Psychiatry, 36, 773-782.

Sroufe, A. (1983). Infant-caregiver attachment and patterns of adaptation in preschool: The roots of maladaptation and competence. In M. Perlmutter(Ed.), Minnesota Symposium on Child Psychiatry (pp. 41-83). Hillsdale, NJ: Erlbaum.

Symons, D. K., \& Moran, G. (1987). The behavioral dynamics of mutual responsiveness in early face-to-face mother-infant interactions. Child Development, 58, 1488-1495.

Tronick, E., Als, H., \& Brazelton, T. B. (1980). Monadic phases: A structural descriptive analysis of infant-mother face-to-face interaction. Merrill-Palmer Quarterly of Behavior and Development, 26, 324.

Tronick, E. Z., \& Cohn, J. F. (1989). Infant-mother face-to-face interaction: Age and gender differences in coordination and miscoordination. Child Development, 59, 85-92.

Tronick, E. Z., Rjcks, M., \& Cohn, J. F. (1982). Maternal and infant affective exchange: Patterns of adaptation. In T. Field \& A. Fogel (Eds.), Emotion and early interaction (pp. 83-100). Hillsdale, NJ: Erlbaum.

Vaughn, B. E., Taraldson, B., Crichton, L., \& Egeland, B. (1980). Relationship between neonatal behavioral organization and infant behavior during the first year of life. Infant Behavior and Development, 3 , 47-66.

Weissman, M. M., \& Paykel, E. S. (1974). The depressed women: A study in social relationships. Chicago: University of Chicago Press.

Received December 16, 1987 Revision received October 24, 1988 Accepted January 24, 1989

\section{Publication Practices and Scientific Conduct}

The recent disclosures of fraud in the conduct of research, reporting of research, or both in a number of scientific disciplines have prompted a widespread program of self-examination of publication practices and ethics.

The editor joins with APA in reminding authors of the principles of good publication practices and scientific conduct. Prospective authors are directed to the Publication Manual of the American Psychological Association (3rd ed.) and to the "Instructions to Authors" printed in this issue. The requirements of data availability, replicability, authorship credit, ethical treatment of subjects, and primary publication of data are important-they are meant to ensure responsible science and appropriate use of scarce and valuable resources. 